\title{
A Zinc-Rich Coating Fabricated on a Magnesium Alloy by Oxide Reduction
}

\author{
Dongzhu Lu ${ }^{1,2,3, *}$, Yanliang Huang ${ }^{1,2,3} \mathbb{D}^{\text {, Jizhou Duan }}{ }^{1,2,3}$ and Baorong Hou ${ }^{1,2,3}$ \\ 1 CAS Key Laboratory of Marine Environmental Corrosion and Bio-fouling, Institute of Oceanology, \\ Chinese Academy of Science, Qingdao 266071, China; hyl@qdio.ac.cn (Y.H.); duanjz@qdio.ac.cn (J.D.); \\ brhou@qdio.ac.cn (B.H.) \\ 2 Open Studio for Marine Corrosion and Protection, Pilot National Laboratory for Marine Science \\ and Technology (Qingdao), Qingdao 266237, China \\ 3 Center for Ocean Mega-Science, Chinese Academy of Sciences, Qingdao 266071, China \\ * Correspondence: 1dz@qdio.ac.cn
}

Received: 1 April 2019; Accepted: 24 April 2019; Published: 25 April 2019

\begin{abstract}
The corrosion resistance of magnesium alloys could be enhanced by covering metallic coatings on the surface. The zinc-rich coating is one of these metallic coatings. To fabricate a zinc-rich coating on magnesium alloys, the substrate should be pretreated carefully, and a protective atmosphere is usually required. In this research, a zinc-rich coating was successfully fabricated on the AZ91D magnesium alloy in air by a diffusion alloying method, with zinc oxide as the zinc source. At the same time, the pretreatment of the magnesium alloy matrix was greatly simplified. The as-diffusion-alloyed zinc-rich intermetallic layer was investigated, utilizing SEM, EDS, and XRD, respectively. It is inferred that zinc oxide was reduced into $\mathrm{Zn}$ atoms by the active $\mathrm{Mg}$ atoms, and the $\mathrm{Mg}$ atoms were coming from the magnesium alloy matrix. Then the $\mathrm{Zn}$ atoms passed through the oxide film and formed an intermetallic layer on the magnesium alloy surface. Thus, taking advantage of the activity of $\mathrm{Mg}$ atoms, magnesium alloys could be surface alloyed with oxides.
\end{abstract}

Keywords: magnesium alloy; zinc oxide; diffusion; coating; surface treatment

\section{Introduction}

Magnesium alloys are lightweight alloys, and could be utilized in various fields [1-3]. The corrosion resistance of magnesium alloys is poor [4-6], which limits further utilization of magnesium alloys.

Coatings are fabricated on the surface to enhance the corrosion resistance of magnesium alloys [7-19]. Among which, the zinc coating is an effective one. It is reported that the weight loss of pure $\mathrm{Zn}$ is about half of the weight loss of pure $\mathrm{Mg}$ in the same duration after exposed to humid air [20]. Adding a little magnesium into pure zinc would reduce the weight loss further [20].

Moreover, zinc-rich coatings are frequently utilized in the electroplating method to fabricate protective coatings on magnesium alloys [17,21]. Magnesium alloys are active, and they are prone to react with oxygen and water to form $\mathrm{MgO}$ and $\mathrm{Mg}(\mathrm{OH})_{2}$ on the surface, which would lead to a weak adhesion of as-electrodeposited coatings [17,21]. Thus, before electroplating, magnesium alloys should be pretreated. Zinc immersion is one of the general processes to pretreat magnesium alloys before plating.

Before the zinc immersion process, several pretreatment processes, including surface cleaning, alkaline cleaning, acid pickle, and acid activation, are commonly enlisted to remove soil, debris, oil, grease, oxides, etc. [17]. Then the magnesium alloy is immersed in special solutions for the zinc film to form [21]. 
The zinc-rich coating could also be fabricated by a thermal evaporation method [18]. In this method, a vacuum environment is required, and the temperature for the evaporation of the original $\mathrm{Zn}$ powder is $600{ }^{\circ} \mathrm{C}$. Similarly, the magnesium specimen could be obtained by thermal diffusion, which buries the magnesium alloy specimen into the pure $\mathrm{Zn}$ powder, and keeps the diffusion system at an elevated temperature for the zinc-rich coating to grow. In this method, the diffusion system could be buried in compact carbon powder to further prevent oxidation [19].

Thus, it is crucial to clean the surface of a magnesium alloy matrix to prohibit the formation of the magnesium oxide film in the zinc immersion method, and it is also crucial to keep a relatively inert atmosphere, to prohibit the oxidation of pure metals in the thermal evaporation method and the thermal diffusion method. It seems as though oxides are always unfavorable, and should be avoided.

In this research, a method based on the diffusion alloying process, but utilizing zinc oxide as the diffusion source instead of pure $\mathrm{Zn}$ powder to fabricate zinc-rich coatings on magnesium alloys, is raised. The pretreatment process of the magnesium alloy matrix is simplified effectively by this method. Meanwhile, the environment requirement, such as a vacuum or inert atmosphere, becomes unnecessary.

\section{Experimental Procedures}

An as-cast AZ91D magnesium alloy with the composition of $9.1 \mathrm{wt} . \% \mathrm{Al}, 0.52 \mathrm{wt} . \% \mathrm{Zn}, 0.26 \mathrm{wt} . \%$ $\mathrm{Mn}$ and $\mathrm{Mg}$ as balance, was utilized as the matrix. Samples were cut into specimens with a dimension of $15 \mathrm{~mm} \times 10 \mathrm{~mm} \times 3 \mathrm{~mm}$ from the AZ91D magnesium alloy sheets with an electrical discharge cutting machine, and then polished with $\mathrm{SiC}$ papers to 1000 grit, rinsed with alcohol, and naturally dried up.

The diffusion source is a mixture of $1 \mathrm{~g} \mathrm{NH}_{4} \mathrm{Cl}$ powder and $10 \mathrm{~g} \mathrm{ZnO}$ powder. Photographs of the $\mathrm{NH}_{4} \mathrm{Cl}$ powder and the $\mathrm{ZnO}$ powder are shown in Figure 1. The magnesium alloy specimens were inserted in the diffusion source. The diffusion source and the magnesium alloy specimens were put into a $30 \mathrm{~mL}$ crucible for the following heat treatment. A schemetic diagram of the diffusion system is shown in Figure 2.
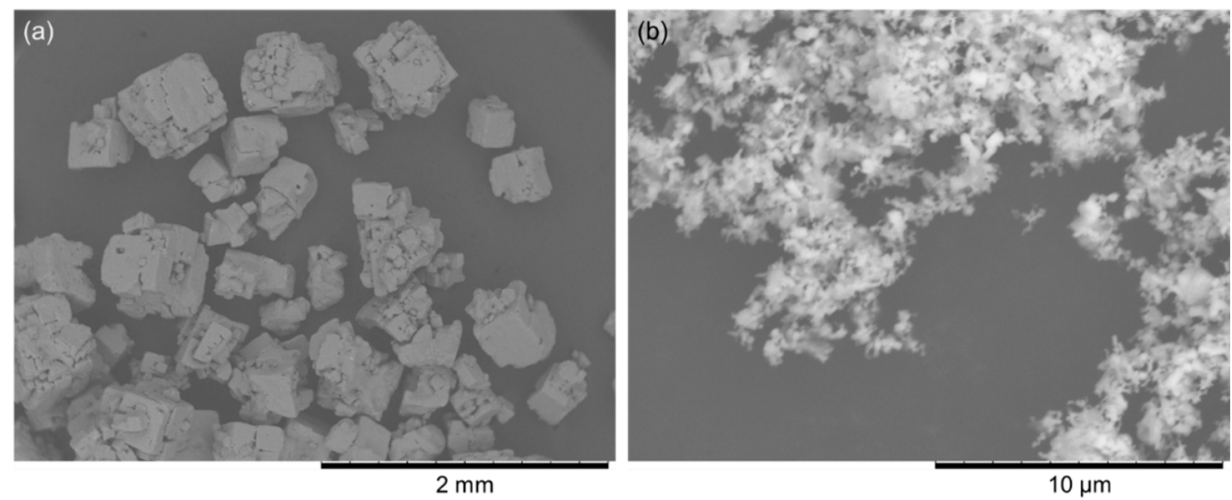

Figure 1. Photographs of the $\mathrm{NH}_{4} \mathrm{Cl}$ powder (a) and the $\mathrm{ZnO}$ powder (b). 


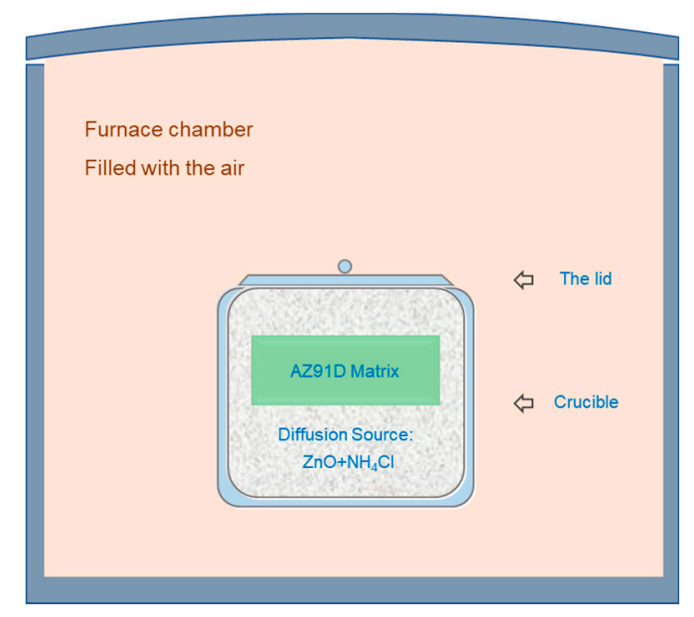

Figure 2. Schematic diagram to show the diffusion system, $\mathrm{ZnO}$ was the only $\mathrm{Zn}$ donor in the diffusion source, and the diffusion alloying process was carried out directly in the air.

After the furnace temperature reached $430{ }^{\circ} \mathrm{C}$ and was kept stable for minutes, the filled crucible was put into the furnace as quickly as possible, and kept at $430^{\circ} \mathrm{C}$ for $2 \mathrm{~h}$ for the surface alloying process on the magnesium alloy specimen to proceed. The whole surface alloying process was carried out in the air; neither vacuum nor inert gases were utilized. After the surface alloying process, specimens were taken out from the furnace and cooled down naturally in the air.

Then the residual powder on the magnesium alloy specimens was cleaned up, and the as-surface alloyed specimens were washed with running water and alcohol successively, and then naturally dried up. Cross-sections of the as-surface alloyed magnesium alloy specimens were obtained with a saw. Then the cross-sections were polished and etched successively for microstructure observation. The polished cross-sections were etched until the as-surface alloyed coating showed up clearly on the specimen surface, and then washed with alcohol and naturally dried up. Microstructure photographs and composition analysis results of the as-diffusion-alloyed specimens were obtained by a scanning electronic microscope (S-3400N, Hitachi, Tokyo, Japan). Phase identification was carried out utilizing an X-ray diffractometer (Ultima IV, Rigaku, Tokyo, Japan). The Gibbs free energies of relative chemical reactions were calculated by a software (HSC 6.0).

\section{Results}

After being diffusion alloyed at $430^{\circ} \mathrm{C}$ for $2 \mathrm{~h}$ with $10 \mathrm{~g} \mathrm{ZnO}$ and $1 \mathrm{~g} \mathrm{NH}_{4} \mathrm{Cl}$ as the diffusion source, a coating was fabricated on the AZ91D magnesium alloy specimen as shown in Figure 3a. It could be figured out that the thickness of the as-diffusion alloyed coating can be hundreds of micrometers. From a magnified photograph of the coating shown in Figure 3b, it could be observed that the coating contains multiple phases. Some phases have a network shape morphology, while other phases are embedded in the network. Dendrites could be observed clearly. The size of the dendrites embedded in the networks is estimated to be tens of micrometers to two hundred micrometers. 

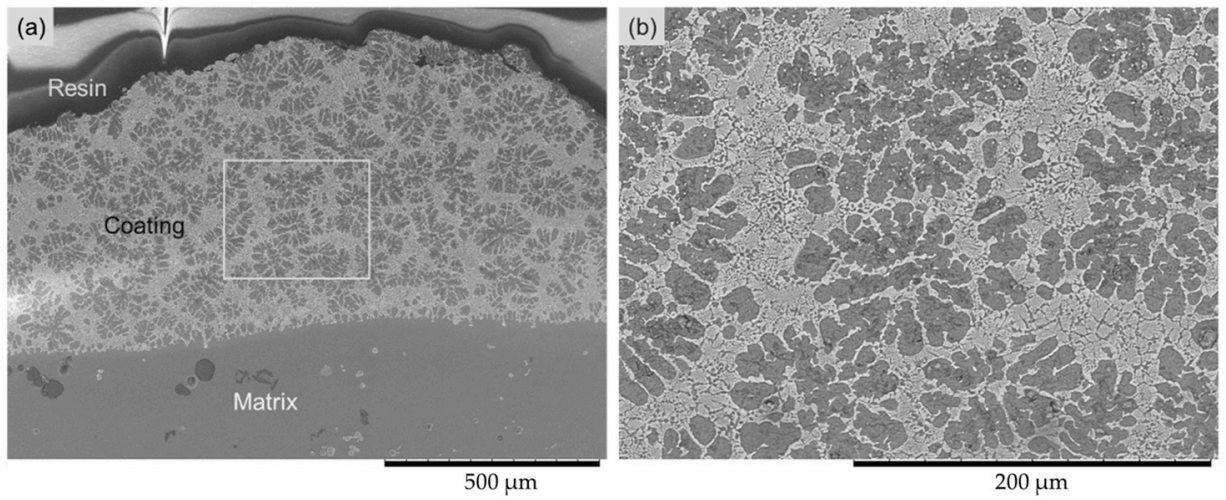

Figure 3. A Cross-section of the as-diffusion-alloyed intermetallic layer on an AZ91D magnesium alloy specimen with zinc oxide as the only $\mathrm{Zn}$ donor in the diffusion source (a) and partially enlarged zone (b) which is marked with a rectangle in (a).

From the microstructure observation of the coating, it could be inferred that the formation of the coating is not a simple solid diffusion process, liquid phase should also be involved in the surface alloying process, since a pure solid diffusion process is driven by the concentration gradient which commonly results in a layer structure, while solidification of a molten phase is prone to result in a network shape eutectic multiple-phase-microstructure [10]. The existence of a liquid phase in the diffusion alloying process is reasonable [22], because the eutectic temperature in the $\mathrm{Mg}-\mathrm{Zn}$ binary system could even be $341^{\circ} \mathrm{C}$, according to the Mg-Zn binary phase diagram [20].

From the EDS results shown in Figure 4, it could be figured out that there are mainly $\mathrm{Mg}, \mathrm{Zn}, \mathrm{Al}$, and $\mathrm{O}$ elements in the coating. $\mathrm{Mg}$ is the dominant element in the AZ91D magnesium alloy matrix. Compared to the original content which was $0.52 \mathrm{wt} . \%$ in the AZ91D magnesium matrix, the relative content of $\mathrm{Zn}$ increased significantly in the magnesium alloy surface, which could be attributed to the continuous input of $\mathrm{Zn}$ atoms from the diffusion source. There was $9.1 \mathrm{wt} . \% \mathrm{Al}$ in the original AZ91D magnesium specimen, hence $\mathrm{Al}$ could also be found in the coating. The existence of the $\mathrm{O}$ element is inferred to be related to the oxidation of active metallic atoms on the cross-section of the AZ91D magnesium alloy specimen.
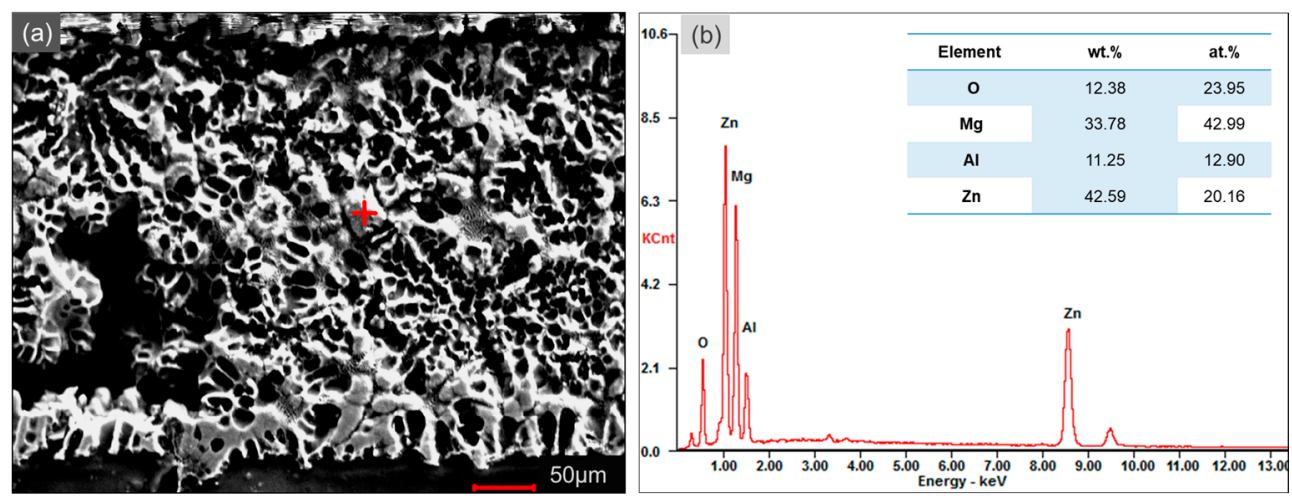

Figure 4. (a) The morphology of a cross-section of the intermetallic layer on a surface-alloyed AZ91D magnesium alloy specimen with zinc oxide as the only Zn donor in the diffusion source; (b) The EDS result of the point located at the cross marked in (a).

Major elements in the surface-alloyed coating on the AZ91D magnesium alloy specimen could be figured out from the element maps shown in Figure 5. Comparing with which in the matrix, the relative content of $\mathrm{Mg}$ is obviously less in the coating. Whereas, $\mathrm{Zn}$ is richer in the coating compared with which in the matrix, since the main source of $\mathrm{Zn}$ is the diffusion source, which was composed of the 
$\mathrm{ZnO}$ powder and the $\mathrm{NH}_{4} \mathrm{Cl}$ powder outside the specimen. Besides, the $\mathrm{Al}$ element and the $\mathrm{O}$ element could also be observed in the coating.
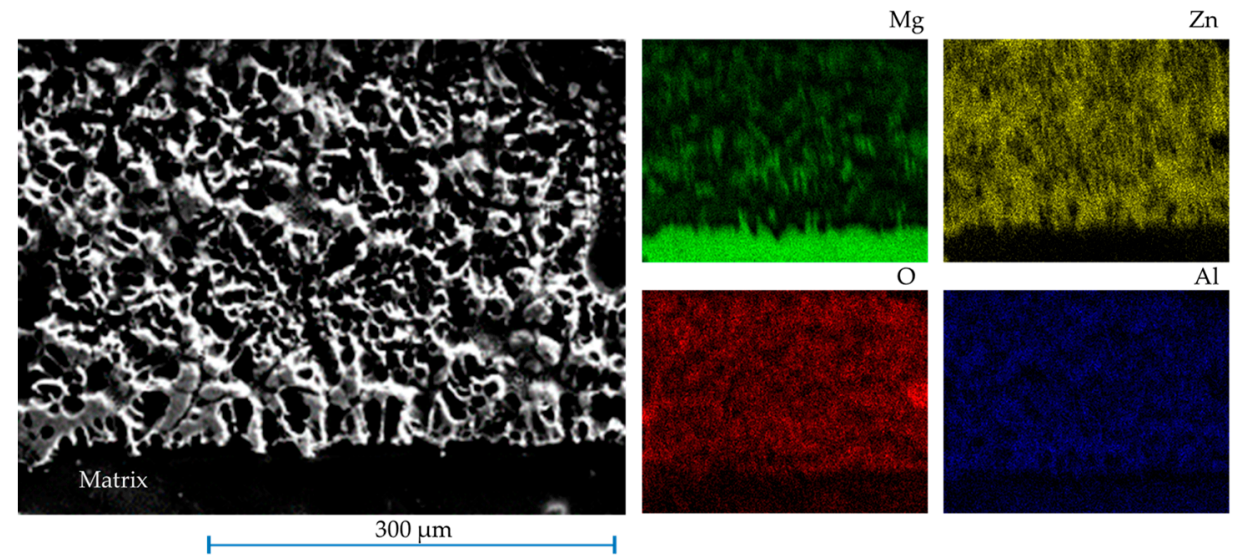

Figure 5. Morphology of a cross-section of the intermetallic layer on an as-surface-alloyed AZ91D magnesium alloy specimen obtained with zinc oxide as the $\mathrm{Zn}$ donor and the corresponding $\mathrm{Mg}, \mathrm{Zn}, \mathrm{O}$, Al element maps.

From the XRD pattern shown in Figure 6, it could be figured out that there are $\mathrm{Mg}_{0.97} \mathrm{Zn}_{0.03}$, $\mathrm{MgO}, \mathrm{Mg}_{32}(\mathrm{Al}, \mathrm{Zn})_{49}, \mathrm{Mg}_{7} \mathrm{Zn}_{3}, \mathrm{AlMg}_{4} \mathrm{Zn}_{11}, \mathrm{Al}_{2} \mathrm{Mg}$ phases in the as-diffusion-alloyed coating. $\mathrm{MgO}$ is inferred to be formed in the duration when the cross-section of the coating was exposed in the air, and other phases including $\mathrm{Mg}_{0.97} \mathrm{Zn}_{0.03}, \mathrm{Mg}_{32}(\mathrm{Al}, \mathrm{Zn})_{49}, \mathrm{Mg}_{7} \mathrm{Zn}_{3}, \mathrm{AlMg}_{4} \mathrm{Zn}_{11}, \mathrm{Al}_{2} \mathrm{Mg}$ are inferred to be in the original coating. Comparing with a binary alloy system, the constituent of a ternary alloy system is much more complex. According to the melting points, these phases would solidify one by one from the melt in the cooling process [16].

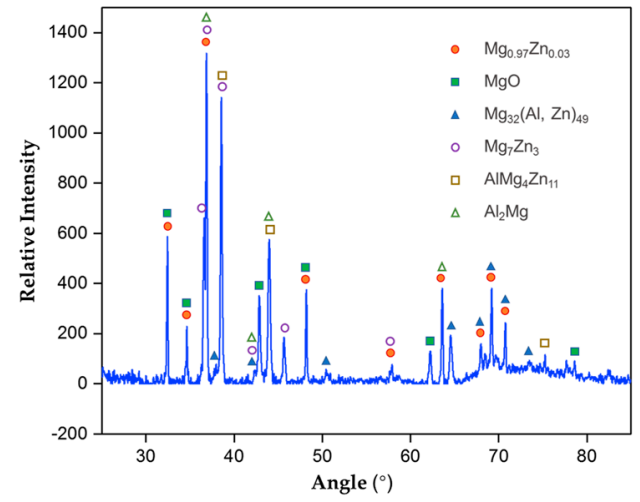

Figure 6. The XRD pattern of the intermetallic layer fabricated by surface alloying on the AZ91D magnesium alloy with $\mathrm{ZnO}$ as the only $\mathrm{Zn}$ donor.

\section{Discussion}

Since the Zn element in the coating is significantly increased compared with which in the AZ91D magnesium matrix, there should be a $Z n$ element input continuously from the diffusion source. As there was only $\mathrm{ZnO}$, which contains $\mathrm{Zn}$ in the diffusion source, $\mathrm{ZnO}$ is inferred to be reduced into $\mathrm{Zn}$ atoms, and $\mathrm{Zn}$ atoms were transferred and dissolved into the surface of the AZ91D magnesium alloy specimen. Relative chemical reactions are listed as follows [23].

$$
\begin{gathered}
\mathrm{NH}_{4} \mathrm{Cl}=\mathrm{NH}_{3}(\mathrm{~g})+\mathrm{HCl}(\mathrm{g}) \\
2 \mathrm{Mg}+\mathrm{O}_{2}(\mathrm{~g})=2 \mathrm{MgO}
\end{gathered}
$$




$$
\begin{aligned}
\mathrm{MgO}+\mathrm{HCl}(\mathrm{g}) & =\mathrm{Mg}(\mathrm{OH}) \mathrm{Cl} \\
\mathrm{Mg}(\mathrm{l}) & =\mathrm{Mg}(\mathrm{g}) \\
\mathrm{Mg}(\mathrm{s}) & =\mathrm{Mg}(\mathrm{g}) \\
\mathrm{Mg}+\mathrm{ZnO} & =\mathrm{MgO}+\mathrm{Zn}
\end{aligned}
$$

$\mathrm{NH}_{4} \mathrm{Cl}$ is unstable at the diffusion alloying temperature of $430{ }^{\circ} \mathrm{C}$, and it would decompose into $\mathrm{NH}_{3}$ gas and $\mathrm{HCl}$ gas $[23,24]$ as shown in Equation (1). $\mathrm{HCl}$ gas could promote the oxidation of $\mathrm{Mg}$ atoms at the AZ91D magnesium alloy surface as shown in Equations (2) and (3). The oxide film on the AZ91D magnesium alloy specimen surface could be compact or porous. Whereas even a compact oxide film formed initially, this compact film could be converted into a porous one with the help of gaseous $\mathrm{HCl}$ [24] as shown in Equation (3). A porous oxide film on the AZ91D magnesium alloy specimen is much more helpful for the mass transport between the AZ91D magnesium alloy matrix and the diffusion source.

It is reported that in Al-rich magnesium alloys, the oxidation of $\mathrm{Mg}$ is more preferred than $\mathrm{Al}$ [4], and the content of $\mathrm{Al}$ could increase at some positions on the magnesium alloy surface, thus as a result, local melts could emerge. The existence of liquid $\mathrm{Mg}$ has the possibility of releasing gaseous $\mathrm{Mg}$ further [4], as shown in Equation (4), and the sublimation of solid Mg may also happen [25] as shown in Equation (5). Liquid $\mathrm{Mg}$, gaseous $\mathrm{Mg}$ and $\mathrm{Mg}$ atoms could react with $\mathrm{ZnO}$ to produce $\mathrm{Zn}$ atoms as shown in Equation (6).

Meanwhile, oxidation of $\mathrm{Mg}$ is reported to occur at the interface between the $\mathrm{MgO}$ film and the air in a regular oxidation process of magnesium alloys [4,5]. In the diffusion alloying process here, the $\mathrm{MgO}$ film contacted with the mixed powder which contains $\mathrm{ZnO}$ directly, thus it is possible for the active $\mathrm{Mg}$ atoms to pass through the $\mathrm{MgO}$ film and react with $\mathrm{ZnO}$ to produce $\mathrm{Zn}$ atoms as shown in Figure 7.

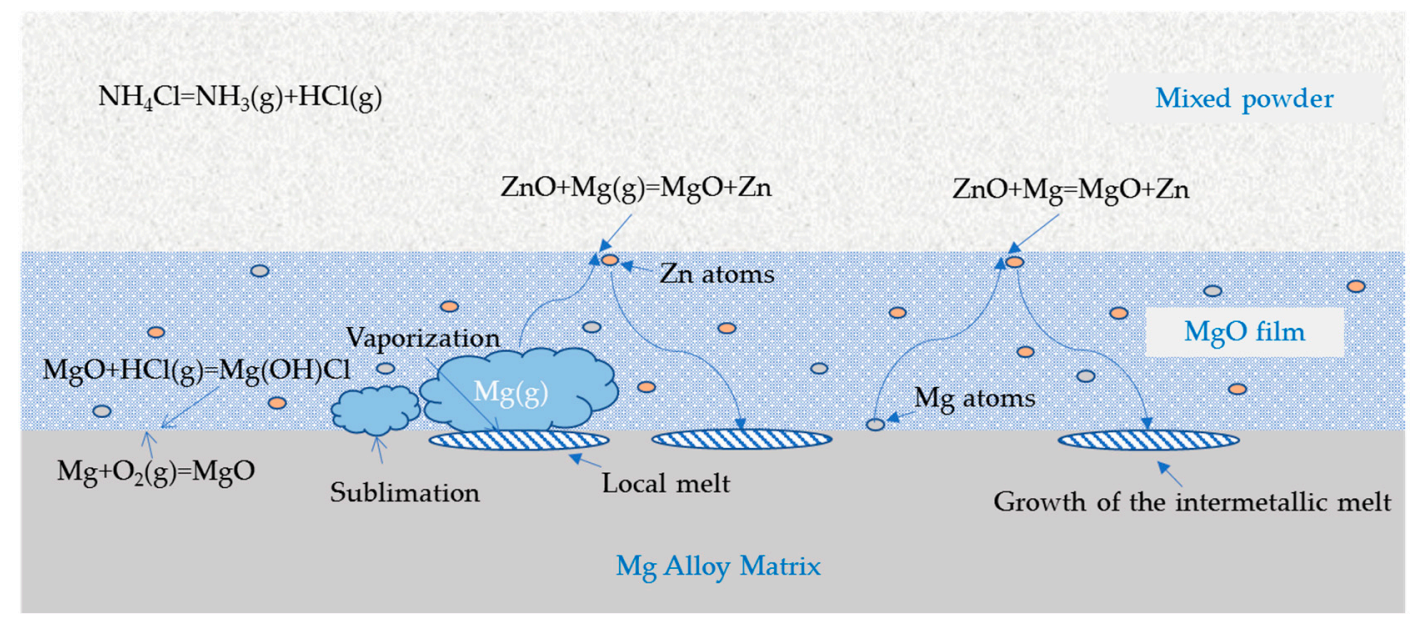

Figure 7. Schematic diagram of the in-situ reduction of $\mathrm{ZnO}$ by the active $\mathrm{Mg}$.

$\mathrm{Zn}$ atoms are transported into the magnesium alloy surface continuously through vacancies in the $\mathrm{MgO}$ film, and a $\mathrm{Zn}$-rich layer would form on this magnesium alloy. Since the eutectic temperature of the $\mathrm{Mg}-\mathrm{Zn}$ binary system could be $341{ }^{\circ} \mathrm{C}$ which is below the diffusion alloying temperature, the $\mathrm{Zn}$-rich layer would be molten in the diffusion alloying process. In the cooling process, the melt solidified gradually, and the coating which composed of various phases formed.

The Gibbs free energies of relative chemical equations are shown in Figure 8. It could be found that most of the chemical equations are preferred, except Equations (4) and (5). Although pure liquid $\mathrm{Mg}$ and pure solid $\mathrm{Mg}$ both have difficulty becoming pure gaseous $\mathrm{Mg}$ in the thermal calculations which describe the preference of reactions under ideal conditions as shown in Figure 8, the Gibbs 
energies of Equations (4) and (5) may change in a real sophisticated diffusion alloying system. In fact, these reactions are reported in some literatures [25,26]. The existence of $\mathrm{Al}$ and $\mathrm{Zn}$ both in the intermetallic melt and in the magnesium alloy matrix could affect the evaporation of liquid $\mathrm{Mg}$ and the sublimation of solid $\mathrm{Mg}$. It could be easier for an $\mathrm{Mg}$ atom in the liquid or solid phase in the magnesium alloy surface to become an $\mathrm{Mg}$ atom in the gaseous phase, considering that the melting point of $\mathrm{Mg}$ could be reduced by adding $\mathrm{Al}$ and $\mathrm{Zn}$ into the $\mathrm{Mg}$ solid solution.

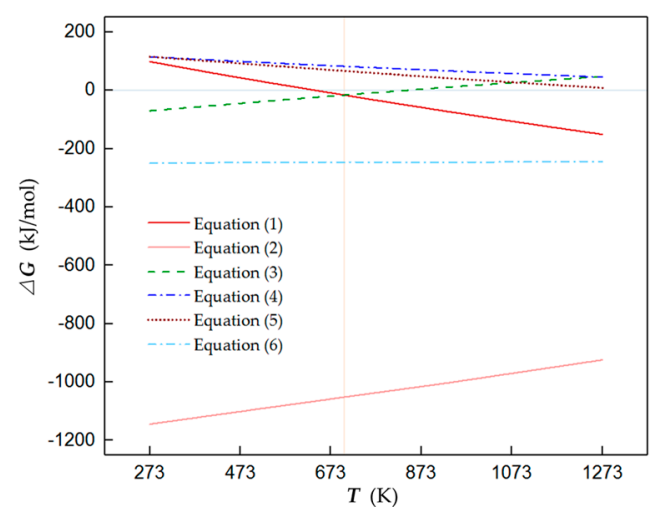

Figure 8. Gibbs free energies of relative chemical equations.

\section{Conclusions}

To conclude, it is possible to fabricate a Zn-rich coating on magnesium alloys by the powder thermal diffusion alloying method with $\mathrm{ZnO}$ powder as the only $\mathrm{Zn}$ donor. Some $\mathrm{ZnO}$ powder could be reduced to produce $\mathrm{Zn}$ atoms by taking advantage of the intrinsic activity of $\mathrm{Mg}$ atoms in the magnesium alloy matrix. As the $\mathrm{MgO}$ film is full of vacancies, the as-reduced $\mathrm{Zn}$ atoms would diffuse into the magnesium alloy matrix across the porous $\mathrm{MgO}$ film.

This method is an economic method to fabricate $\mathrm{Zn}$-rich coatings on magnesium alloys. Since stable $\mathrm{ZnO}$ is utilized as the raw material, transport and storage of the diffusion source would be much easier.

Author Contributions: Conceptualization, D.L.; Methodology, D.L.; Software, D.L.; Validation, D.L.; Formal Analysis, D.L.; Investigation, D.L.; Resources, D.L.; Data Curation, D.L.; Writing-Original Draft Preparation, D.L.; Writing-Review \& Editing, D.L.; Visualization, D.L.; Supervision, Y.H., J.D. and B.H.; Project Administration, D.L.; Funding Acquisition, D.L.

Funding: This research was funded by the Key Research \& Development Program of Shandong Province, China [No: 2018GSF117039] and the Applied Research Program of Qingdao, China [No: 17-1-1-22-jch].

Acknowledgments: The authors would like to thank all the anonymous reviewers for their kind help and useful advice.

Conflicts of Interest: The authors declare no conflict of interest.

\section{References}

1. Szklarz, Z.; Bisztyga, M.; Krawiec, H.; Lityńska-Dobrzyńska, L.; Rogal, Ł. Global and local investigations of the electrochemical behavior the T6 heat treated Mg-Zn-RE magnesium alloy thixo-cast. Appl. Surf. Sci. 2017, 405, 529-539. [CrossRef]

2. Wan, Y.; Gao, Y.; Jiang, S.; Liu, C.; Chen, Z. Manufacturing high-performance Mg alloy through hot extrusion. Mater. Manuf. Process. 2018, 33, 863-866. [CrossRef]

3. Lu, D.; Huang, Y.; Jiang, Q.; Zheng, M.; Duan, J.; Hou, B. An approach to fabricating protective coatings on a magnesium alloy utilising alumina. Surf. Coat. Technol. 2019, 367, 336-340. [CrossRef]

4. Tan, Q.; Atrens, A.; Mo, N.; Zhang, M.X. Oxidation of magnesium alloys at elevated temperatures in air: A review. Corro. Sci. 2016, 112, 734-759. [CrossRef]

5. Czerwinski, F. The reactive element effect on high-temperature oxidation of magnesium. Inter. Mater. Rev. 2015, 60, 264-296. [CrossRef] 
6. Esmaily, M.; Svensson, J.; Fajardo, S.; Birbilis, N.; Frankel, G.; Virtanen, S.; Arrabal, R.; Thomas, S.; Johansson, L. Fundamentals and advances in magnesium alloy corrosion. Prog. Mater. Sci. 2017, 89, 92-193. [CrossRef]

7. Fu, Z.; Chen, X.; Liu, B.; Liu, J.; Han, X.; Deng, Y.; Hu, W.; Zhong, C. One-step fabrication and localized electrochemical characterization of continuous Al-alloyed intermetallic surface layer on magnesium alloy. Coatings 2018, 8, 148. [CrossRef]

8. Han, J.; Blawert, C.; Tang, S.; Yang, J.; Hu, J.; Zheludkevich, M.L. Effect of surface pre-treatments on the formation and degradation behaviour of a calcium phosphate coating on pure magnesium. Coatings 2019, 9, 259. [CrossRef]

9. Song, J.; Cui, X.; Jin, G.; Cai, Z.; Liu, E.; Li, X.; Chen, Y.; Lu, B. Self-healing conversion coating with gelatin-chitosan microcapsules containing inhibitor on AZ91D alloy. Surf. Eng. 2018, 34, 79-84. [CrossRef]

10. Gu, C.; Wang, L.; Hu, X.; Dong, W.; DaCosta, H. Borate's effects on coatings by PEO on AZ91D alloy. Surf. Eng. 2017, 33, 773-778. [CrossRef]

11. Shigematsu, I.; Nakamura, M.; Saitou, N.; Shimojima, K. Surface treatment of AZ91D magnesium alloy by aluminum diffusion coating. J. Mater. Sci. Lett. 2000, 19, 473-475. [CrossRef]

12. Zhang, M.; Kelly, P. Surface alloying of AZ91D alloy by diffusion coating. J. Mater. Res. 2002, 17, 2477-2479. [CrossRef]

13. Youping, M.; Xu, K.; Wen, W.; He, X.; Liu, P. The effect of solid diffusion surface alloying on properties of ZM5 magnesium alloy. Surf. Coat. Technol. 2005, 190, 165-170. [CrossRef]

14. Zhu, L.; Song, G. Improved corrosion resistance of AZ91D magnesium alloy by an aluminium-alloyed coating. Surf. Coat. Technol. 2006, 200, 2834-2840. [CrossRef]

15. Lu, D.; Zhang, Q.; Wang, X.; Yang, L.; Ma, X.; Wang, W.; Huang, Y. Intermetallic layer obtained by the compact powder diffusion alloying method on AZ91D magnesium alloy in air. Surf. Coat. Tech. 2017, 309, 986-993. [CrossRef]

16. Lu, D.; Zhang, Q.; Wang, W.; Guan, F.; Ma, X.; Yang, L.; Wang, X.; Huang, Y.; Hou, B. Effect of cooling rate and the original matrix on the thermal diffusion alloyed intermetallic layer on magnesium alloys. Mater. Design 2017, 120, 75-82. [CrossRef]

17. Gray, J.; Luan, B. Protective coatings on magnesium and its alloys-A critical review. J. Alloy. Compd. 2002, 336, 88-113. [CrossRef]

18. Wang, X.; Wang, X.; Wang, D.; Zhao, M.; Han, F. A novel approach to fabricate Zn coating on Mg foam through a modified thermal evaporation technique. J. Mater. Sci. Tech. 2018, 34, 1558-1563. [CrossRef]

19. Chen, Y.; Liu, T.; Lu, L.; Wang, Z. Thermally diffused antimony and zinc coatings on magnesium alloys AZ31. Surf. Eng. 2012, 28, 382-386. [CrossRef]

20. Prosek, T.; Nazarov, A.; Bexell, U.; Thierry, D.; Serak, J. Corrosion mechanism of model zinc-magnesium alloys in atmospheric conditions. Corro. Sci. 2008, 50, 2216-2231. [CrossRef]

21. Zhao, M.; Cai, C.; Wang, L.; Zhang, Z.; Zhang, J. Effect of zinc immersion pretreatment on the electro-deposition of Ni onto AZ91Dmagnesium alloy. Surf. Coat. Technol. 2010, 205, 2160-2166. [CrossRef]

22. Hirmke, J.; Zhang, M.X.; St John, D.H. Surface alloying of AZ91E alloy by Al-Zn packed powder diffusion coating. Surf. Coat. Technol. 2011, 206, 425-433. [CrossRef]

23. Luo, B.; Zhu, Q.; Cheng, Y.; Wang, L.; Li, X. The integrated cleaning process of soda and vinyl chloride on the chemical looping of $\mathrm{NH}_{4} \mathrm{Cl}$ decomposition. Chem. React. Eng. Technol. 2015, 31, 449-458. (In Chinese)

24. Lu, D.; Jiang, Q.; Zheng, M.; Zhang, J.; Huang, Y.; Hou, B. The role of ammonium chloride in the powder thermal diffusion alloying process on a magnesium alloy. Coatings 2019, 9, 252. [CrossRef]

25. Zhang, Z.; Fu, X.; Mao, M.; Yu, Q.; Mao, S.; Li, J.; Zhang, Z. In situ observation of sublimation-enhanced magnesium oxidation at elevated temperature. Nano Res. 2016, 9, 2796-2802. [CrossRef]

26. Czerwinski, F. Oxidation characteristics of magnesium alloys. JOM 2012, 64, 1477-1483. [CrossRef]

(C) 2019 by the authors. Licensee MDPI, Basel, Switzerland. This article is an open access article distributed under the terms and conditions of the Creative Commons Attribution (CC BY) license (http://creativecommons.org/licenses/by/4.0/). 